\title{
"CLINICAL AND LABORATORY PROFILE AND THERAPEUTIC RESPONSE OF SCRUB TYPHUS IN CHILDREN IN A TERTIARY CARE CENTRE IN NEPAL"
}

\author{
Agrawal $S^{1^{*}}$, Subedi $K H^{2}$, Shah $R K^{3}$, Jha $S^{4}$, Pun $S B^{5}$
}

\section{Affiliation}

1. Consultant Pediatrician, Department of Pediatrics, Kanti Children's Hospital, Maharajgunj, Nepal

2. Senior Consultant Pediatrician, Department of Pediatrics, Rapti Health Sciences Academy, Dang, Nepal

3. Pediatrician, Department of Pediatrics, Sukraraj Tropical and Infectious Disease Hospital, Teku, Nepal

4. Senior Medical Officer, Department of Pediatrics, Sukraraj Tropical and Infectious Disease Hospital, Teku, Nepal

5. Co-ordinator, Clinical Research Unit, Sukraraj Tropical and Infectious Disease Hospital, Teku, Nepal

\section{ARTICLE INFO}

Received : 31 August, 2019

Accepted : 26 January, 2020

Published : 3o June, 2020

(c) Authors retain copyright and grant the journal right of first publication with the work simultaneously licensed under Creative Commons Attribution License CC - BY 4.0 that allows others to share the work with an acknowledgment of the work's authorship and initial publication in this journal.

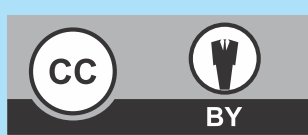

ORA 152

DOI: https://doi.org/10.3126/bjhs.v5i1.29608

* Corresponding Author

Dr. Sumit Agrawal

Consultant Pediatrician

Department of Pediatrics

Kanti Children's Hospital, Maharajgunj, Nepal

Email: shilpy62@gmail.com

ORCID ID: https://orcid.org/0000-0002-9863-9325

\section{Citation}

Agrawal S, Subedi KH, Shah RK, Jha S, Pun SB. "Clinical and Laboratory Profile and Therapeutic response of Scrub Typhus in Children in a Tertiary Care Centre in Nepal”. BJHS 2020;5(1)11:897-901.

\section{ABSTRACT}

\section{Introduction}

Scrub typhus is the most common rickettsial infection from the Indian subcontinent. It is caused by the organism Orienta tsutsugamushi inhabiting in trombiculid mites and transmitted to humans by the bite of these mites. The disease has a variety of clinical manifestations in children. As this is a common disease in our country so a retrospective study was conducted to study the clinical and laboratory profile and therapeutic outcomes of scrub typhus in children.

\section{Methodology}

A retrospective study was conducted at Sukraraj Tropical and Infectious disease Hospital, Teku, Kathmandu, Nepal after obtaining ethical clearance from Institutional Review Committee, and reviewing the medical records of serologically confirmed scrub typhus in children aged less than 14 years admitted to the hospital between March 2017 and February 2018. Relevant data were entered in excel spreadsheet and analyzed using SPSS 20.

\section{Result}

A total of 20 children were enrolled in the study. Of them $70 \%$ were female, with the mean age being $11.45 \pm 3.1$ years (range 3-14 years) and majority were from Dhading district (40\%). All the children had fever; while there was cough, loss of appetite, rashes, headache, myalgia, arthralgia and hepatosplenomegaly in 45\%, 90\%, 20\%, 55\%, 35\%, 35\% and $30 \%$ of chidren respectively. There was thrombocytopenia in $50 \%$ of children; while hyponatremia, elevation of SGOT and SGPT was present in $30 \%, 70 \%$ and $55 \%$ of patients respectively. Azithromycin was used for treatment in $95 \%$ of children and all had defervescence of fever.

\section{Conclusion}

Scrub typhus should be suspected in children having prolonged fever with organomegaly, thrombocytopenia and elevated transaminases. Azithromycin can be used effectively in children diagnosed as scrub typhus.

\section{KEY WORDS}

Fever, organomegaly, scrub typhus, thrombocytopenia, transaminases. 


\section{INTRODUCTION}

Rickettsial diseases are now established as re-emerging zoonotic bacterial infections in the Indian subcontinent and are an important but often under-recognised cause of febrile illness among children. ${ }^{1}$ Among the wide range of rickettsial diseases, scrub typhus is one of the most commonly recognized diseases in the Asia-Pacific region. ${ }^{2}$ Scrub typhus is a febrile disease endemic to the AsiaAustralia-Pacific region, where $\approx 1$ million cases occur annually. ${ }^{3}$ Historically, the burden of scrub typhus in children has been high. The proportion of pediatric cases ranged from $50 \%$ to $74 \%$ in southern China and Taiwan respectively while $52 \%$ of children were found to be seropositive in central Thailand. ${ }^{4}$ Scrub typhus is now the most commonly reported rickettsial infection from the Indian subcontinent. ${ }^{5}$ It is caused by the organism Orientia tsutsugamushi (O. tsutsugamushi). Trombiculid mites (Leptotrombidium deliense, L. palladium etc) are the natural hosts of the pathogen. Humans are accidental hosts. The disease is transmitted to humans by the bite of mites. Clinical manifestations include febrile illness with various symptoms ranging from headache, gastrointestinal upset, myalgia and self-limiting state to variable severity like acute respiratory distress syndrome (ARDS), meningoencephalitis, acute kidney injury (AKI), myocarditis leading to heart failure, hepatitis and multi organ dysfunction (MOD). ${ }^{6}$

There are recent reports of scrub typhus from various parts of Nepal that might be due to altered environmental factors that occurred after the 2015 earthquake..$^{7-9}$ These altered environmental factors include collapse of many houses causing the rats to come out of their usual underground habitat and resulting in intimate contact between human beings and rats. Apart from that, natural disaster like earthquake would compel human beings to alter their living conditions, predisposing them to overcrowding and unsanitary conditions which could accentuate the linkage between vector, pathogen and man. Pediatric age group constitutes almost half of the cases of scrub typhus. ${ }^{10}$ Despite this fact, there are very few literatures regarding the clinical and laboratory profile of children diagnosed with scrub typhus in Nepal. Hence, the aim of the study was to understand the clinico-laboratory profile and therapeutic outcome of serologically confirmed scrub typhus in children in Nepal.

\section{METHODOLOGY}

A retrospective study was conducted at Sukraraj Tropical and Infectious disease Hospital, Teku, Kathmandu, Nepal over a period of one year from $1^{\text {st }}$ March 2017 to $28^{\text {th }}$ February 2018. A total of 20 patients aged less than 14 years with serologically diagnosed scrub typhus were included in the study. Demographic, clinical and laboratory data were obtained and analyzed. ELISA test kit manufactured by Biotrol Laboratories Pvt. Ltd., New Delhi was used to detect O. tsutsugamushi on serum samples collected from suspected patients. The sensitivity of the test was $99 \%$ and specificity was $96 \%$ and serological agreement of $96.5 \%$ with that of Immunofluoresecnt Assay (IFA). Prior to start of the study ethical clearance was obtained from the Institutional Review Committee of the Hospital. Scrub typhus was suspected, if a patient presented with an acute undifferentiated febrile illness of 5 days or more with or without eschar, or if eschar was present, fever of less than 5 days duration was considered. ${ }^{11}$ Leukocytosis and leucopenia were defined as total leukocyte count more than $11,000 / \mathrm{mm}^{3}$ and less than $4,000 / \mathrm{mm}^{3}$ respectively. Thrombocytopenia and severe thrombocytopenia was defined as platelet count less than $1,50,000 / \mathrm{mm}^{3}$ and $50,000 / \mathrm{mm}^{3}$ respectively. Data was entered into an excel spreadsheet and analyzed using SPSS 20. Categorical variables were reported as frequencies and percentages. Continuous variables were reported as mean \pm $\mathrm{SD}$ (parametric) or median and ranges (non-parametric).

\section{RESULTS}

A total of 20 patients with serologically confirmed scrub typhus were enrolled during the study period. Of the total, $14(70 \%)$ were female. The mean age of the patients was $11.45 \pm 3.1$ years (range 3-14 years). Seventy five percent of all patients were aged above 10 years. The majority of patients were from Dhading district (40\%), followed by Sarlahi (20\%), Kathmandu (20\%) and Nuwakot (10\%), Sindhuli (5\%) and Dhanusha (5\%) respectively. Eighty five percent of the patients were admitted from August through October (Table 1).

\begin{tabular}{|c|c|c|c|}
\hline $\begin{array}{l}\text { S. } \\
\text { N. }\end{array}$ & Variable & Number & $\begin{array}{c}\text { Percentage } \\
(\%)\end{array}$ \\
\hline \multirow[t]{5}{*}{1.} & \multicolumn{3}{|l|}{ Age in Years } \\
\hline & $<1$ year & 0 & 0 \\
\hline & $1-5$ years & 1 & 5 \\
\hline & $6-10$ years & 4 & 20 \\
\hline & $>10$ years & 15 & 75 \\
\hline \multirow[t]{3}{*}{2.} & \multicolumn{3}{|l|}{ Gender } \\
\hline & Male & 6 & 30 \\
\hline & Female & 14 & 70 \\
\hline \multirow[t]{7}{*}{3.} & \multicolumn{3}{|l|}{ Address } \\
\hline & Sarlahi & 4 & 20 \\
\hline & Kathmandu & 4 & 20 \\
\hline & Sindhuli & 1 & 5 \\
\hline & Dhading & 8 & 40 \\
\hline & Dhanusha & 1 & 5 \\
\hline & Nuwakot & 2 & 10 \\
\hline \multirow[t]{6}{*}{4.} & \multicolumn{3}{|l|}{ Month of admission } \\
\hline & Shrawan(July/ August) & 2 & 10 \\
\hline & Bhadra (August/ September) & 7 & 35 \\
\hline & Asoj (September/ October) & 4 & 20 \\
\hline & Kartik (October/ November) & 6 & 30 \\
\hline & Poush (December/ January) & 1 & 5 \\
\hline
\end{tabular}

Table 2 shows the clinical profile of patients infected with scrub typhus. All the children presented with fever. There were 11 (55\%) patients who had fever for 5-10 days and 7 (35\%) having fever $>10$ days. Of the total patients $45 \%$ had cough and $5 \%$ had shortness of breath. Rashes were present among $20 \%$ of patients. Loss of appetite was present in $90 \%$ of patients. The most common non-specific symptom was headache (55\%) followed by myalgia (35\%) and arthralgia 
(35\%). Five percent had hepatomegaly and 25\% had splenomegaly. Organomegaly (either hepatomegaly or splenomegaly was present in $30 \%$ of children.

Table 2: Clinical profile of patients (n=20)
\begin{tabular}{|l|l|c|c|}
\hline $\begin{array}{l}\text { S. } \\
\text { N. }\end{array}$ & Variable & Number & $\begin{array}{c}\text { Percentage } \\
(\%)\end{array}$ \\
\hline 1. & Fever & 10 \\
\hline & $<5$ days & 2 & 55 \\
\hline & $5-10$ days & 11 & 35 \\
\hline & $>10$ days & 7 & 45 \\
\hline 2. & Cough & 9 & 5 \\
\hline 3. & Shortness of breath & 1 & 90 \\
\hline 4. & Loss of appetite & 18 & 55 \\
\hline 5. & Headache & 11 & 35 \\
\hline 6. & Myalgia & 7 & 20 \\
\hline 7. & Vomiting & 4 & 35 \\
\hline 8. & Arthralgia & 7 & 20 \\
\hline 9. & Rashes & 4 & 0 \\
\hline 10. & Lymphadenopathy & 0 & 5 \\
\hline 11. & Hepatomegaly & 1 & 25 \\
\hline 12. & Spleneomegaly & 5 & \\
\hline
\end{tabular}

Table 3 represents the laboratory profile of the study population. Of the notable laboratory findings, anemia was present in $20 \%$ of the patients. There was leucopenia in $25 \%$ and leucocytosis in $15 \%$ of the patients. Fifty percent of the patients presented with thrombocytopenia, while $10 \%$ with severe thrombocytopenia. There was hyponatremia in $30 \%$ of the patients. SGOT levels was found elevated in $70 \%$ of the patients, while $20 \%$ showed more than two times the upper limit of the normal. There was elevation in SGPT levels above the upper limit of the normal in $55 \%$ of the patients.

\begin{tabular}{|c|c|c|c|}
\hline S.N. & Variable & Number & Percentage (\%) \\
\hline 1. & Anemia & 4 & 20 \\
\hline \multirow[t]{4}{*}{2.} & \multicolumn{3}{|l|}{ Total Count } \\
\hline & $<4000$ & 5 & 25 \\
\hline & $4000-11000$ & 12 & 60 \\
\hline & $>11000$ & 3 & 15 \\
\hline \multirow[t]{5}{*}{3.} & \multicolumn{3}{|l|}{ Platelet Count } \\
\hline & $<50,000$ & 2 & 10 \\
\hline & $50,000-1,00,000$ & 2 & 10 \\
\hline & $1,00,000-1,50,000$ & 6 & 30 \\
\hline & $>1,50,000$ & 10 & 50 \\
\hline 4. & Hyponatremia & 6 & 30 \\
\hline \multirow[t]{6}{*}{5.} & \multicolumn{3}{|l|}{ AST (SGOT) } \\
\hline & upto $45 \mathrm{IU} / \mathrm{L}$ & 6 & 30 \\
\hline & 46- $90 \mathrm{IU} / \mathrm{I}$ & 10 & 50 \\
\hline & 91- $180 \mathrm{IU} / \mathrm{L}$ & 1 & 5 \\
\hline & $181-360 \mathrm{IU} / \mathrm{I}$ & 2 & 10 \\
\hline & $>360 \mathrm{IU} / \mathrm{I}$ & 1 & 5 \\
\hline \multirow[t]{5}{*}{6.} & \multicolumn{3}{|l|}{ ALT (SGPT) } \\
\hline & upto $45 \mathrm{IU} / \mathrm{I}$ & 9 & 45 \\
\hline & 46- $90 \mathrm{IU} / \mathrm{I}$ & 8 & 40 \\
\hline & 91- $180 \mathrm{IU} / \mathrm{I}$ & 1 & 5 \\
\hline & $181-360 \mathrm{IU} / \mathrm{I}$ & 2 & 10 \\
\hline
\end{tabular}

Among the children who were diagnosed to be having scrub typhus, $95 \%$ of them received Azithromycin for treatment and only 1 (5\%) received Doxycycline for treatment of the condition. The prescribing drugs used in patients are presented in Table 4. All the children who received either azithromycin or doxycycline for treatment of scrub typhus responded rapidly to therapy. The fever subsided within 6 hours of starting treatment in 3(15\%) patients, within 6-12 hours of starting treatment in $10(50 \%)$ of patients, beyond 12 hours to within 24 hours in $4(20 \%)$ patients and beyond 24 hours in $3(15 \%)$ patients.

Table 4: Drug used for treatment and outcome
\begin{tabular}{|l|l|c|c|}
\hline S. & \multicolumn{1}{|c|}{ Variable } & Number & $\begin{array}{c}\text { Percentage } \\
(\%)\end{array}$ \\
\hline . & \multicolumn{3}{|c|}{} \\
\hline 1. & Drug used for treatment \\
\hline & Azithromycin & 19 & 95 \\
\hline & Doxycycline & 1 & 5 \\
\hline & \multicolumn{3}{|c|}{} \\
\hline 2. & Fever subsidence after treatment (hrs) \\
\hline & $<6$ hrs & 3 & 15 \\
\hline & $6-12$ hrs & 10 & 50 \\
\hline & $>12-24$ hrs & 4 & 20 \\
\hline & $>24-48$ hrs & 3 & 15 \\
\hline
\end{tabular}

\section{DISCUSSION}

Scrub typhus is an important cause of acute undifferentiated fever in the Indian Subcontinent. ${ }^{12}$ There has been a rapid surge in scrub typhus in children in recent years. The mean age at presentation was $11.45( \pm 3.1)$ years which was in contrast to many studies which reported the mean age between 4.4 to 8.9 years, ${ }^{5,10,13}$ which might be due to the relatively small sample size of the study population. Of the children enrolled in the study, only $30 \%$ were male while most studies have reported the percentage of males ranging from $52.5 \%$ to $61.7 \% .{ }^{14-16}$ Among the admitted children, $40 \%$ were from Dhading district which was one of the most severely affected by the 2015 Gorkha earthquake. ${ }^{17}$ The majority of patients were admitted from August through October accounting for $85 \%$ of cases, similar to those reported by Sah et $\mathrm{al}^{10}$ who had conducted the study in Nepal. Similar findings were noted in studies done by Bal et $\mathrm{al}^{15}$ Kalal et $\mathrm{al}^{18}$ and Sankhyan et $\mathrm{al}^{19}$ in India. But the study conducted by Kumar et al noted the peak incidence of scrub typhus cases between the months of September to February $^{14}$ which might be due to the variation in climate. So further studies are required to establish the temporal variation of scrub typhus cases.

Children with scrub typhus usually have non-specific symptoms. Fever was present in all the patients in this study, as reported by other studies by Sah et al, ${ }^{10}$ Planivel et al, ${ }^{12}$ Maina et al $^{13}$ and Kumar et al. ${ }^{14}$ Majority of children had fever for 5-10 days which was similar to findings of studies done by Sood et $\mathrm{al}^{20}$ and Sankhyan et al. ${ }^{19}$ But other studies done by Sah et $\mathrm{al}^{10}$ and Kumar et $\mathrm{al}^{14}$ have shown the duration of fever to be between 7-14 days in majority of children. This 
difference might just have been due to the variation in the categorization of range taken for the duration of fever. Of the respiratory symptoms, cough was the predominant symptom occurring in $45 \%$ of patients which was similar to the findings of the study done by Kumar et al, ${ }^{14}$ Krishnan et $\mathrm{al}^{21}$ and Lurshay et al. ${ }^{22}$ Although presence of eschar is pathognomonic of the disease, ${ }^{23}$ typical eschar was not documented in the study population. However there was presence of rashes in $20 \%$ of patients. Loss of appetite was present in $90 \%$ of patients which was very high as compared to the study done by Lurshay et al $^{22}$ who had documented it to be $46.7 \%$. Headache was present in $55 \%$ of patients which was similar in studies done by Bal et al, ${ }^{15}$ Lurshay et al ${ }^{22}$ and Gopalakrisna et al. ${ }^{24}$ There was myalgia in $35 \%$ of patients which was similar to the study done by Gopalakrisna et $\mathrm{al}^{24}$ but various other studies have shown it to be between 23$26 \%{ }^{14,21,22}$ Hepatosplenomegaly was present in $30 \%$ of patients which was similar to study done by Sah et al $^{10}$ and Bal et al. ${ }^{15}$ However the study done by Basu et $a l^{16}$ had shown a much higher presence of hepatosplenomegaly $52.5 \%$ in their study population. Although lymphadenopathy occurs in between $23 \%$ to $93 \%$ of children with scrub typhus, ${ }^{23}$ there was no lymphadenopathy in our children.

Thrombocytopenia was one of the major laboratory finding occurring in $50 \%$ of the study population which was similar to the results reported by Bal et al, ${ }^{15}$ Kalal et al, ${ }^{18}$ Krishnan et $\mathrm{al}^{21}$ and Lurhsay et al. $^{22}$ Among patients with thrombocytopenia, severe thrombocytopenia was present in $10 \%$ of children which was similar to the results reported by Krishnan et $\mathrm{al}^{21}$ and Sah et al $^{10}$ but contrary to the results reported by Sankhyan et al of $47 \% .{ }^{19}$ There was leucopenia in $25 \%$ of the children which is much higher than the results reported by Sah et $\mathrm{al}^{10}$ of $8.1 \%$ and Gopalakrisna et al of 3.7\%. ${ }^{24}$ There was leucocytosis in $15 \%$ of children which was similar to the results reported by Gopalakrisna et $\mathrm{al}^{24}$ but was lower in contrary to the results reported by Kumar et $\mathrm{al}^{14}$ of $37 \%$, Sankhyan et $\mathrm{al}^{19}$ of $47 \%$ and Lurshay et $\mathrm{al}^{22}$ of $46.7 \%$. There was hyponatremia in $30 \%$ of children which was similar to the results reported by Sah et $\mathrm{al}^{10}$ and Lurshay et $\mathrm{al}^{22}$ but in major contrast to those reported by Krishnan et al of $80.5 \%{ }^{21}$ There was elevation of liver enzymes with SGOT being elevated in $70 \%$ of children in the present study whereas Palanivel et $\mathrm{al}^{12}{ }^{12} \mathrm{Bal}$ et $\mathrm{al}^{15}$ and Sankhyan et $\mathrm{al}^{19}$ reported it to be $64.17 \%, 81.8 \%$ and $100 \%$ respectively. In the present study there was elevation of SGPT in 55\% of children whereas Bal et al, ${ }^{15}$ Sankhyan et al ${ }^{19}$ and Krishnan et $\mathrm{al}^{21}$ reported it to be elevated in $73.3 \%, 100 \%$ and $74 \%$ respectively in their study population.
Azithromycin was used for the treatment in $95 \%$ of children diagnosed with scrub typhus in the present study and Doxycycline was used in only $5 \%$. This may be because of the fact that in our country Doxycycline is available only as $100 \mathrm{mg}$ capsules, and may have caused dilemma to the treating doctor to prescribe Doxycyxline. Azithromycin is available as suspension as well as tablets so it is easier to prescribe to children. Doxycycline was commonly used for treatment of scrub typhus in children in studies done by Bhat et al, ${ }^{5}$ Kumar et al $^{14}$ and Bal et al. ${ }^{15}$ All the children received specific treatment for a total of 7 days. Data from several randomized control trials support that Azithromycin is equally effective in the management of scrub typhus in children. ${ }^{23}$ There was defervescence within 24 hours of starting treatment in $85 \%$ of children in the present study whereas it was $73.15 \%$ in the study conducted by Krishnanet al. $^{21}$ There was defervescence within 18-47 hours in the study reported by Kumar et al, ${ }^{14}$ within 26 hours in the study reported by Bhat et $\mathrm{al}^{5}$ and within 24-53 hours in the study reported by Wangrangsimakul et al. ${ }^{4}$ In our study all of the children diagnosed with scrub typhus improved after treatment. There were no children with shock, coagulopathy or respiratory distress. This might be due to the small sample size.

\section{CONCLUSIONS}

Scrub typhus should be suspected in all children presenting with acute undifferentiated fever of more than 1 week duration with hepatosplenomegaly with thrombocytopenia and elevated transaminases. The present study shows azithromycin can be effectively used in these children with higher treatment rates.

\section{LIMITATONS OF THE STUDY}

The sample size was small so more studies are required to understand scrub typhus in children in Nepal.

\section{ACKNOWLEDGEMENT}

We are thankful to all the staffs of the medical record section of Sukraraj Tropical and Infectious Disease Hospital, Teku for their efforts to collect data of all the admitted patients.

\section{CONFLICT OF INTEREST}

We declare no conflict of interest.

\section{FINANCIAL DISCLOSURE}

We declare no conflict of interest. 


\section{REFERENCES}

1. Khan SA, Dutta P, Khan AM, Topno R, Borah J, Chowdhury P, Mahanta $J$. Re-emergence of scrub typhus in northeast India. International Journal of Infectious Diseases. 2012 Dec 1;16(12):e889-90. DOI: 10.1016/j.ijid.2012.05.1030

2. Kelly DJ, Fuerst PA, Ching WM, Richards AL. Scrub typhus: the geographic distribution of phenotypic and genotypic variants of Orientia tsutsugamushi. Clinical Infectious Diseases. 2009 Mar 15;48(Supplement_3):S203-30. DOI: 10.1086/596576

3. Rosenberg R. Drug-resistant scrub typhus: Paradigm and paradox. Parasitology today (Personal ed.). 1997 Apr;13(4):131-2. DOI: 10.1016/S0169-4758(97)01020-X

4. Wangrangsimakul T, Greer RC, Chanta C, Nedsuwan S, Blacksell SD, Day NP, Paris DH. Clinical Characteristics and Outcome of Children Hospitalized With Scrub Typhus in an Area of Endemicity. Journal of the Pediatric Infectious Diseases Society. 2019 Mar 13. DOI: 10.1093/jpids/piz014

5. Bhat NK, Pandita N, Saini M, Dhar M, Ahmed S, Shirazi N, Wasim S, Shirke R, Chandar V. Scrub typhus: A clinico-laboratory differentiation of children with and without meningitis. Journal of tropical pediatrics. 2016 Feb 6;62(3):194-9. DOI: 10.1093/tropej/fmv097

6. Rajapakse S, Rodrigo C, Fernando D. Scrub typhus: pathophysiology, clinical manifestations and prognosis. Asian Pacific journal of tropical medicine. 2012 Apr 1;5(4):261-4. DOI: 10.1016/S19957645(12)60036-4

7. Nayak N. Scrub typhus in Nepal. Nepal journal of epidemiology. 2016 Jun;6(2):563. DOI: 10.3126/nje.v6i2.15162

8. Bastola A, Marahatta SB, Jha S, Pant N. Aftermath earthquake in Nepal: burden of scrub typhus cases and their presentations. Journal of Tropical Diseases. 2017;5(1):236. DOI: 10.4172/2329$891 x .1000236$

9. Bastola A, Pant N. An outbreak of scrub typhus in nepal following the 2015 Gorkha earthquake. International Journal of Infectious Diseases. 2016 Dec 1;53:55. DOI: 10.1016/j.ijid.2016.11.141

10. Sah RK, Chapagain RH, Shrestha SM, Rai GK. Clinico-laboratory Profile and Therapeutic Outcome of Serologically Confirmed Scrub Typhus in Children in Tertiary Care Children's Hospital of Nepal. Pediatric Infect Dis. 2019;4(1):1. DOI: 10.21767/2573-0282.100065

11. EDCD interim Guideline on Prevention and Control of Scrub Typhus September 2015 (Updated in August 2016)

12. Palanivel S, Nedunchelian K, Poovazhagi V, Raghunadan R, Ramachandran P. Clinical profile of scrub typhus in children. The Indian Journal of Pediatrics. 2012 Nov 1;79(11):1459-62. DOI: 10.1007/s12098-012-0721-0

13. Maina AN, Farris CM, Odhiambo A, Jiang J, Laktabai J, Armstrong J, Holland T, Richards AL, O'Meara WP. Q fever, scrub typhus, and rickettsial diseases in children, Kenya, 2011-2012. Emerging infectious diseases. 2016 May;22(5):883. DOI: 10.3201/eid2205. 150953
14. Kumar M, Krishnamurthy S, Delhikumar CG, Narayanan P, Biswal N, Srinivasan S. Scrub typhus in children at a tertiary hospital in southern India: clinical profile and complications. Journal of infection and public health. 2012 Feb 1;5(1):82-8. DOI: 10.1016/j.jiph.2011.11.001

15. Bal M, Mohanta MP, Sahu S, Dwibedi B, Pati S, Ranjit M. Profile of Pediatric Scrub Typhus in Odisha, India. Indian pediatrics. 2019 Apr 1;56(4):304-6. PMID:31064899

16. Basu S, Saha A, Sarkar S, Sinha MK, Das MK, Datta R, Hazra A, Datta Kanjilal S, Datta S. Clinical Profile and Therapeutic Response of Scrub Typhus in Children: A Recent Trend from Eastern India. Journal of tropical pediatrics. 2018 May 23;65(2):139-46. DOI: 10.1093/ tropej/fmy027

17. Dahal RK. Engineering geological issues after Gorkha earthquake 2015 in Nepal-a preliminary understanding. In10th Asian Regional Conference of IAEG 2015 Sep.

18. Kalal BS, Puranik P, Nagaraj S, Rego S, Shet A. Scrub typhus and spotted fever among hospitalised children in South India: Clinical profile and serological epidemiology. Indian journal of medical microbiology. 2016;3(34):293-8. DOI: 10.4103/0255-0857.188315

19. Sankhyan N, Saptharishi LG, Sasidaran K, Kanga A, Singhi SC. Clinical profile of scrub typhus in children and its association with hemophagocytic lymphohistiocytosis. Indian pediatrics. 2014 Aug 1;51(8):651-3. DOI: 10.1007/s13312-014-0470-4

20. Sood AK, Chauhan L, Gupta H. CNS manifestations in Orientia tsutsugamushi disease (scrub typhus) in north India. The Indian Journal of Pediatrics. 2016 Jul 1;83(7):634-9. DOI: 10.1007/s12098015-2001-2

21. Krishnan R, Pillai RK, Elizabeth KE, Shanavas A, Bindusha S. Pediatric scrub typhus in Southern Kerala: An emerging public health problem. Clinical Epidemiology and Global Health. 2016 Jun 1;4(2):89-94. DOI: 10.1016/j.cegh.2016.03.003

22. Lurshay RM, Gogoi PR, Deb S. Clinico-laboratory profile of severe pediatric scrub typhus. Sch J App Med Sci. 2016;4(10C):3714-20. DOI: $10.21276 /$ sjams.2016.4.10.32

23. Reller ME, Dumler JS. Scrub Typhus. In: Kliegmen RM, St. Geme JW, editors. Nelson Textbook of Pediatrics. 21st ed. Canada: Elsevier; 2020. p. 6545-50.

24. Gopalakrisna MV, Suryaprakash H, Kumar GS, Kumar KJ, Murthy DS. Clinical Features, Laboratory Findings and Complications of Scrub Typhus in South Indian Children. Journal of Nepal Paediatric Society. 2017 Oct 4;37(1):21-4. DOI: 10.3126/jnps.v37i1.16202 